\title{
SGC-GAK-1: a chemical probe for cyclin G associated kinase (GAK)
}

Christopher R. M. Asquith, ${ }^{\dagger}$ Benedict-Tilman Berger, ${ }^{\ddagger}, \perp$ Jing Wan,,${ }^{\S} \wedge$ James M. Bennett,,$\supset$ Stephen J. Capuzzi, ${ }^{\propto}$ Daniel J. Crona, ${ }^{\nabla, \wedge}$ David H. Drewry, ${ }^{\dagger}$ Michael P. East, ${ }^{\ddagger \ddagger}$ Jonathan M. Elkins, ${ }^{\supset, \subset}$ Oleg Fedorov, $\supset$ Paulo H. Godoi, $\subset$ Debra M. Hunter,,${ }^{\circledR}$ Stefan Knapp, ${ }^{\ddagger, \perp}$ Susanne Müller, ${ }^{\ddagger}$ Chad D. Torrice, ${ }^{\nabla}$ Carrow I. Wells, ${ }^{\dagger}$ H. Shelton Earp,,$^{\S}{ }^{\wedge}$ Timothy M. Willson, ${ }^{\dagger}$ and William J. Zuercher ${ }^{\dagger,,^{*}}$

†Structural Genomics Consortium, UNC Eshelman School of Pharmacy, University of North Carolina at Chapel Hill, Chapel Hill, NC 27599, US

‡Structural Genomics Consortium, Johann Wolfgang Goethe University, Buchmann Institute for Molecular Life Sciences, Max-von-Laue-Str. 15, D-60438 Frankfurt am Main, DE

${ }^{\perp}$ Institute for Pharmaceutical Chemistry, Johann Wolfgang Goethe University, Max-von-Laue-Str. 9, D-60438

Frankfurt am Main, DE

§Department of Medicine, University of North Carolina at Chapel Hill, Chapel Hill, NC 27599, US

${ }^{\wedge}$ Lineberger Comprehensive Cancer Center, University of North Carolina at Chapel Hill, NC 27599, US

`Structural Genomics Consortium and Target Discovery Institute, Nuffield Department of Clinical Medicine, University of Oxford, Old Road Campus Research Building, Oxford, OX 37 DQ, UK

${ }^{\propto}$ Division of Chemical Biology and Medicinal Chemistry, UNC Eshelman School of Pharmacy, University of North Carolina at Chapel Hill, Chapel Hill, NC 27599, US

${ }^{\nabla}$ Division of Pharmacotherapy and Experimental Therapeutics, UNC Eshelman School of Pharmacy, University of North Carolina at Chapel Hill, Chapel Hill, NC 27599, US

${ }^{\ddagger}$ Department of Pharmacology, University of North Carolina at Chapel Hill, Chapel Hill, NC 27599, US

`Structural Genomics Consortium, Universidade Estadual de Campinas, Campinas, São Paulo, 13083-886, BR

ABSTRACT: We describe SGC-GAK-1 (11), a potent, selective, and cell-active inhibitor of cyclin G-associated kinase (GAK), together with a structurally-related negative control SGC-GAK-1N (14). 11 was highly selective in an in vitro kinome-wide screen, but cellular engagement assays defined RIPK2 as a collateral target. We identified $\mathbf{1 8}$ as a potent RIPK2 inhibitor lacking GAK activity. Together, the chemical probe set of 11, 14, and $\mathbf{1 8}$ can be used to interrogate the cellular biology of GAK inhibition.

\section{Introduction}

Cyclin G-associated kinase (GAK) is a $160 \mathrm{kDa}$ serine/threonine kinase originally identified as a direct association partner of cyclin G. ${ }^{1}$ GAK is a member of the numb-associated kinase (NAK) family, which includes AAK1 (adaptor protein 2-associated kinase), STK16/MPSK1 (serine/threonine kinase 16/myristoylated and palmitoylated serine/threonine kinase 1), and $\mathrm{BMP}_{2} \mathrm{~K} / \mathrm{BIKE}$ (BMP-2 inducible kinase). ${ }^{2}$ In addition to its kinase domain, the C-terminus of GAK protein has high homology with auxilin and tensin. ${ }^{3}$ GAK is ubiquitously expressed and within the cell localizes to the Golgi complex, cytoplasm, and nucleus. ${ }^{4}$

Genetic studies have implicated GAK in several diverse biological processes. Genome-wide association studies have identified single nucleotide polymorphisms in the
GAK gene associated with susceptibility to Parkinson's disease. ${ }^{5}$ GAK, like other members of the NAK family, is involved in membrane trafficking and sorting of proteins and as an essential cofactor for $\mathrm{HSC}_{70}$-dependent uncoating of clathrin-coated vesicles in the cytoplasm. ${ }^{6,7} \mathrm{GAK}$ is also required for maintenance of centrosome maturation and progression through mitosis. ${ }^{8}$ GAK is over-expressed in osteosarcoma cell lines and tissues where it contributes to proliferation and survival. ${ }^{9}$ Notably, GAK expression increases during prostate cancer progression to androgen independence and is correlated with the Gleason score in surgical specimens from prostate cancer patients. ${ }^{10,11}$

We have a program to develop small molecule chemical probes to elucidate the biological role of kinases such as GAK that belong the lesser-studied portion of the kinome. ${ }^{12}$ To be useful research reagents, these chemical 
probes must be potent, selective, and cell-active. ${ }^{13}$ Specifically the aspirational criteria we follow are (i) in vitro biochemical $\mathrm{IC}_{50}<50 \mathrm{nM}$; (ii) $\geq 30$-fold selective relative to other kinases in a large assay panel such as DiscoverX KINOMEscan; and (iii) cellular activity or target engagement $\mathrm{IC}_{50}<1 \mu \mathrm{M}$. In addition, the probe should be accompanied by a structurally related negative control that is at least several orders of magnitude less potent at the primary kinase target. ${ }^{13}$

A number of quinazoline-based kinase inhibitors show cross reactivity with GAK, including the approved drugs gefitinib and erlotinib (Figure 1) ${ }^{14}$ These drugs were designed as inhibitors of either epidermal growth factor receptor (EGFR) or SRC kinase and show similar or higher affinity for several other kinases, making them ineffective tools for studying GAK biology. Thus, $t$ is not known whether the efficacy or adverse events observed with these kinase inhibitor drugs are associated with their cross-activity on GAK. Notably, it has been proposed that GAK inhibition causes toxicity due to pulmonary alveolar dysfunction. This hypothesis is based in part on the phenotype of transgenic mice expressing catalytically inactive GAK but has not yet been tested with a selective small molecule GAK inhibitor. ${ }^{15}$
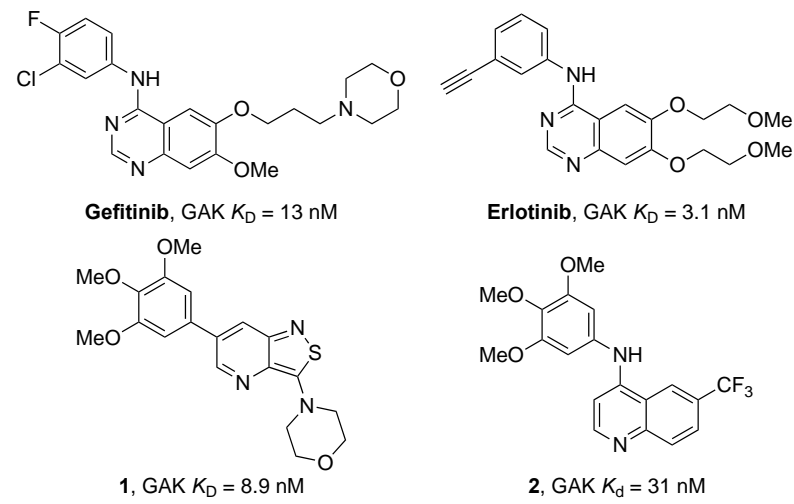

Figure 1. Previously described inhibitors of GAK.

Isothiazolo[5,4-b]pyridine $\mathbf{1}$ has been described as a selective inhibitor of GAK but shows cross reactivity with other kinases, including KIT, PDGFRB, FLT3, and MEK ${ }_{5}{ }^{16}$ any of which could lead to confounding biology in cells. The availability of a GAK chemical probe with improved selectivity would be a valuable tool to probe GAK biology. We previously described 4-anilinoquinoline inhibitors of GAK, exemplified by $2 .{ }^{17}$ The optimization of this series to a GAK chemical probe is described.

\section{Results}

Quinoline 2 was profiled at $1 \mu \mathrm{M}$ across a panel of over 400 wild-type human kinases at DiscoverX using heterogeneous assays employing displacement of kinase protein from an immobilized inhibtor. Subsequent $K_{\mathrm{D}}$ determination for those kinases with $>50 \%$ binding at $1 \mu \mathrm{M}$ identified three kinases (receptor-interacting protein kinase 2, RIPK2; AarF domain containing kinase 3, $\mathrm{ADCK}_{3}$; and nemo-like kinase, NLK) with $K_{\mathrm{D}}$ values within 30 -fold of that of GAK (Table Si). While little is known about the activity of quinazolines on $\mathrm{ADCK}_{3}$, and NLK, a prior study of quinazoline inhibitors of RIPK2 showed H-bonding between Ser25 of RIPK2 near the solvent exposed portion of the ATP-binding pocket. ${ }^{18}$ Since GAK has Ala47 as the corresponding residue, we hypothesized that small, nonpolar substituents at the quinoline 6- and 7-positions might show improved selectivity over RIPK2.

To investigate this hypothesis and define the SAR of $\mathrm{ADCK}_{3}$ and NLK, we profiled several quinolines prepared in our previous study against the three collateral targets (Table 1). ${ }^{17}$ 6,7-Dimethoxyquinoline 3 had the highest GAK affinity but also showed increased binding affinity to RIPK2 relative to 2 . Replacement of either methoxy group with a hydrogen, as in $\mathbf{4}$ and $\mathbf{5}$, led to reduced affinity on all four kinases. Notably, the unsubstituted quinoline $\mathbf{6}$ showed an improved selectivity profile, although it had the poorest affinity for GAK among the analogs. The nitrile isomers $\mathbf{7}$ and $\mathbf{8}$ both retained single digit nanomolar affinity for GAK yet had different effects on selectivity profile: the 6-isomer 7 had an improved selectivity profile while the 7 -isomer 8 showed binding to all three offtargets within ten-fold. A tert-butyl group in the 6position (9) led to improvement of the selectivity profile against RIPK2 and $\mathrm{ADCK}_{3}$ with a decrease in selectivity over NLK compared with 2.

Table 1. Kinase affinity of 4 -anilinoquinolines.

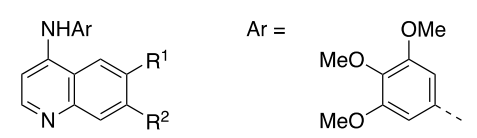

\begin{tabular}{ccccccc} 
& $\mathbf{R}^{\mathbf{1}}$ & $\mathbf{R}^{\mathbf{2}}$ & $\mathbf{G A K}^{\mathbf{a}}$ & $\mathbf{R I P K}^{\mathbf{a}}$ & $\mathbf{A D C K}^{\mathbf{a}}$ & $\mathbf{N L K}^{\mathbf{a}}$ \\
\hline $\mathbf{2}$ & $\mathrm{CF}_{3}$ & $\mathrm{H}$ & 31 & 180 & 220 & 790 \\
$\mathbf{3}$ & $\mathrm{OMe}$ & $\mathrm{OMe}$ & 2.9 & 42 & 250 & 410 \\
$\mathbf{4}$ & $\mathrm{H}$ & $\mathrm{OMe}$ & 17 & 200 & 1200 & 700 \\
$\mathbf{5}$ & $\mathrm{OMe}$ & $\mathrm{H}$ & 21 & 170 & 2000 & 2600 \\
$\mathbf{6}$ & $\mathrm{H}$ & $\mathrm{H}$ & 59 & 2900 & 4100 & 6200 \\
$\mathbf{7}$ & $\mathrm{CN}$ & $\mathrm{H}$ & 3.9 & 88 & 170 & 29 \\
$\mathbf{8}$ & $\mathrm{H}$ & $\mathrm{CN}$ & $9 \cdot 7$ & 96 & 66 & 28 \\
$\mathbf{9}$ & $t-\mathrm{Bu}$ & $\mathrm{H}$ & 25 & 670 & 740 & 350
\end{tabular}

${ }^{a} K_{\mathrm{D}}(\mathrm{nM})$ in competition binding assay (DiscoverX, $\mathrm{n}=2$ ).

Comparison of the two matched molecular pairs with methoxy and nitrile (4 and 8; 5 and 7 respectively) suggested that electron withdrawing substituents at the quinoline 6-position showed improved selectivity and warranted further investigation. The 6-halogenated quinolines 10-12 were prepared as described previously by nucleophilic substitution of 4-chloroquinolines with 3,4,5trimethoxyaniline. ${ }^{17}$ These halogen-substituted analogs (10-12) showed high GAK affinity, all with $K_{\mathrm{D}}<10 \mathrm{nM}$ (Table 2). 11 also displayed remarkable selectivity, with the closest off-target kinase (RIPK2) being > 50-fold weaker in affinity.

To confirm the selectivity profiles across the NAK subfamily, the affinity of $\mathbf{1 1}$ was evaluated in homogeneous time-resolved fluorescence resonance energy transfer 
(TR-FRET)-based ligand binding displacement assays (Figure 2A). 11 displayed an impressive profile of over

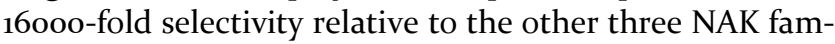
ily members. In addition, a differential scanning fluorimetry (DSF) assay ${ }^{19}$ and isothermal titration calorimetry (ITC) were employed to confirm direct interaction with GAK (Figure 2B and 2C). $\mathbf{1 1}$ increased the thermal stability of the isolated GAK kinase domain, suggesting strong binding of the inhibitor. ITC revealed potent affinity for GAK $\left(K_{\mathrm{D}}=4.5 \mathrm{nM}\right)$. We assessed the kinome selectivity of $\mathbf{1 1}$ in the KINOMEscan assay panel (Figure $2 \mathrm{D}$ and Table S2). $K_{\mathrm{D}}$ values were measured for kinases with binding greater than $50 \%$ at $1 \mu \mathrm{M}$ (Table $\mathbf{S}_{3}$ ). 11 showed $>50$-fold selectivity relative to all 400 kinases. The closest offtargets were RIPK2, $\mathrm{ADCK}_{3}$, NLK and ACVR1.

Table 2. Kinase binding of halogenated quiniolines.

\begin{tabular}{ccccccc} 
& $\mathbf{R}$ & $\mathbf{G A K}^{\mathbf{a}}$ & $\mathbf{R I P K 2}^{\mathbf{a}}$ & ADCK3 $^{\mathbf{a}}$ & $\mathbf{N L K}^{\mathbf{a}}$ \\
\hline $\mathbf{1 0}$ & $\mathrm{Cl}$ & 6.7 & 85 & 170 & 650 \\
$\mathbf{1 1}$ & $\mathrm{Br}$ & 1.9 & 110 & 190 & 520 \\
$\mathbf{1 2}$ & $\mathrm{I}$ & 7.9 & 69 & 190 & 660
\end{tabular}

${ }^{a} K_{\mathrm{D}}(\mathrm{nM})$, competition binding assay (DiscoverX, $\mathrm{n}=2$ ).

An established best practice for the use of chemical probes in biological assays is to test in parallel a compound closely related in structure to the probe but inactive for the target protein. ${ }^{3}$ Demonstration of divergent results between the chemical probe and its negative control increases confidence that the engagement of the target protein is responsible for the observed biology. We designed and prepared two potential negative controls that were anticipated to lack GAK activity. First, 13 incorporated a 2-methylquinoline that would directly hinder hydrogen bonding to the hinge region of the kinase. Second, the $N$-methyl $\mathbf{1 4}$ was expected to disrupt a water network necessary for favorable compound binding (Asquith, C. R. M. and Laitinen, T., unpublished results). Neither compound induced thermal stabilization of GAK protein, and both 13 and 14 demonstrated >10,0oo-fold weaker GAK binding affinity in the TR-FRET assay (Table 3). KINOMEscan and subsequent $K_{\mathrm{D}}$ determinations of $\mathbf{1 3}$ and 14 identified only a single kinase with $<1 \mu \mathrm{M}$ affinity (14: interleukin 1 receptor associated kinase 3, IRAK $3 K_{\mathrm{D}}=$ $740 \mathrm{nM}$ ) (Tables $\mathbf{S}_{2}$ and $\mathbf{S}_{4}$ ). Both compounds were suitable as GAK negative controls, and we selected $\mathbf{1 4}$ based on (a) its higher selectivity in the NAK family ligand binding displacement assay and (b) the structural modification leading to loss of GAK activity was not expected to directly interfere with kinase hinge binding.

Having confirmed potent GAK binding and selectivity relative to other NAK family members, we next sought to demonstrate that activity and selectivity of $\mathbf{1 1}$ in live cells using a NanoBRET target engagement assay..$^{20} 11$ and 14 were evaluated for their ability to displace a fluorescent
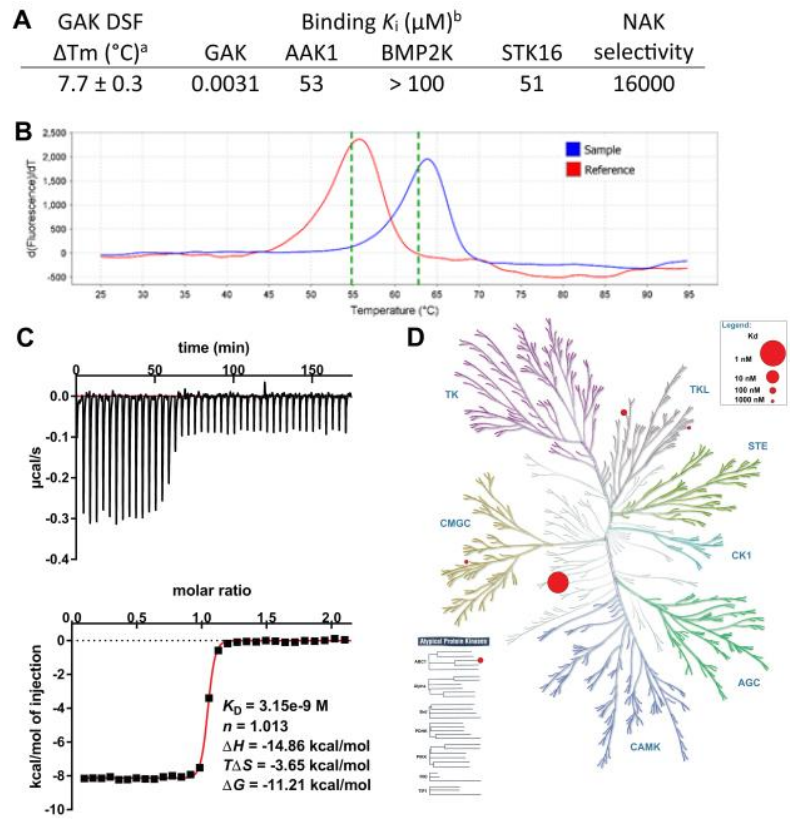

Figure 2. (A) Binding affinity of $\mathbf{1 1}$ for NAK family kinases. aTemperature shift of GAK denaturation as measured by DSF ( $\mathrm{n}=4$ ); 'TR-FRET-based ligand binding displacement assay $(n=1)$. (B) DSF curve of GAK and 11; (C) ITC of GAK with 11; (D) KINOMEscan results.

Table 3. NAK family binding of 13 and 14.
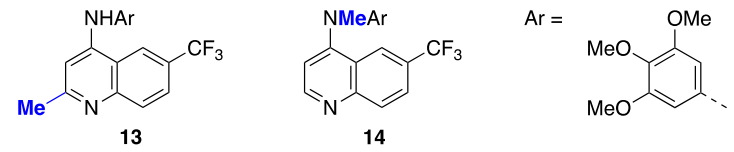

\begin{tabular}{cccccc} 
& GAK $^{\mathbf{a}}$ & AAK1 $^{\mathbf{b}}$ & BMP2K $^{\mathbf{b}}$ & GAK $^{\mathbf{b}}$ & STK16 $^{\mathbf{b}}$ \\
\hline 13 & -0.52 & $>100$ & $>100$ & 19 & $>100$ \\
14 & -0.30 & 78 & 95 & 2.5 & 15
\end{tabular}

${ }^{\mathrm{a}} \Delta T_{\mathrm{m}}\left({ }^{\circ} \mathrm{C}\right)$ measured by DSF; ${ }^{\mathrm{b}} K_{\mathrm{i}}(\mu \mathrm{M})$ in TR-FRET-based ligand binding displacement assay $(n=1)$.

tracer molecule from the ATP binding site of a transiently expressed full length GAK protein $N$-terminally fused with NanoLuc luciferase (Nluc) in HEK293T cells. In the absence of compound, the tracer molecule and fusion protein were in proximity and able to generate an observable bioluminescence resonance energy transfer (BRET) signal. Increasing concentrations of compound displaced the tracer, causing a loss of BRET signal. 11 had high affinity for GAK in cells $\left(\mathrm{IC}_{50}=120 \mathrm{nM}\right)$, although the measured $\mathrm{IC}_{50}$ was 63 -fold higher than the in vitro $K_{\mathrm{D}}$ value. We interpret the difference as most likely due to competition with ATP in cells. The negative control 14 showed no cellular binding to GAK up to $5.0 \mu \mathrm{M}$.

Notably, the previously reported GAK inhibitor 1 displayed GAK cellular potency in the single digit $\mu \mathrm{M}$ range, approximately ten-fold weaker than $\mathbf{1 1}$. We also evaluated 11 and 14 in a RIPK2 NanoBRET assay as this kinase was the closest off-target. We were surprised that $\mathbf{1 1}$ had only three-fold selectivity for GAK over RIPK 2 in cells (Figure 3, GAK IC $\mathrm{IO}_{50}=120 \pm 50 \mathrm{nM}$; RIPK2 $\left.\mathrm{IC}_{50}=360 \pm 190 \mathrm{nM}\right)$. 
The negative control $\mathbf{1 4}$ and the previously described GAK inhibitor 1 showed no affinity for RIPK2 up to $10 \mu \mathrm{M}$.
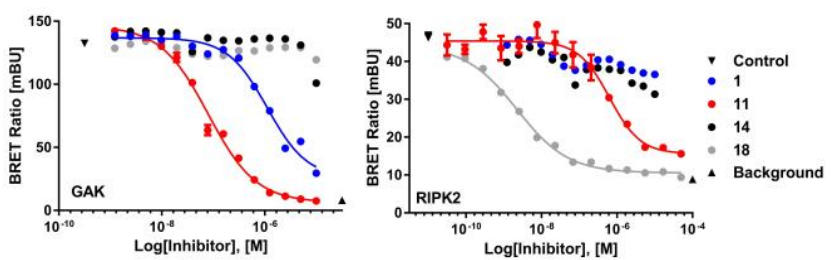

Figure 3. NanoBRET cellular target engagement assays. a. GAK, b. RIPK2. Control: DMSO, tracer present. Background: DMSO, no tracer.

Given the observed cross-activity of $\mathbf{1 1}$ with RIPK2 in cells, we sought to identify an additional control with activity on RIPK2 but not GAK. Surveying known RIPK2 inhibitors (Table 4 and Figure $\mathbf{S} \mathbf{1}$ ), we first evaluated $\mathrm{OD}_{3} 6$ (15), since it had previously been characterized as selective for RIPK2 across a panel of over 400 wild type human kinase assays (although this panel did not include GAK). ${ }^{21}$ We also expected the distinct macrocyclic chemotype of 15 might have a lower propensity for binding GAK relative to a quinoline and were surprised to observe that 15 was nearly equipotent with RIPK2 and GAK in cells. Affinity of 15 for GAK was confirmed in an in vitro binding assay. Next, we selected three quinazoline-based RIPK2 inhibitors (16-18) reported by GlaxoSmithKline. ${ }^{18,22} 16$ and 17 showed high affinity for GAK in the TR-FRET assay and were not subsequently evaluated for cellular target engagement. $\mathbf{8}$ had poor affinity for GAK, both in vitro and in cells (Figure 3). ${ }^{23} \mathbf{1 8}$ demonstrated high affinity for RIPK2 in cells and was thus selected as a RIPK2 control.

Table 4. Evaluation of potential RIPK2 controls.

\begin{tabular}{cccc} 
Compound & GAK $^{\mathbf{a}}$ & GAK $^{\mathbf{b}}$ & RIPK2 $^{\text {b }}$ \\
\hline $\mathbf{1 5}\left(\mathrm{OD}_{36} 6\right)$ & 0.0038 & 0.060 & 0.011 \\
$\mathbf{1 6}\left(\right.$ GSK583 $\left._{5}\right)$ & 0.22 & $\mathrm{nt}$ & $\mathrm{nt}$ \\
$\mathbf{1 7}$ & 0.049 & $\mathrm{nt}$ & $\mathrm{nt}$ \\
$\mathbf{1 8}$ & 8.2 & $>10$ & 0.0020
\end{tabular}

a TR-FRET ligand binding displacement assay $K_{\mathrm{i}}(\mu \mathrm{M}, \mathrm{n}=$ 2); ${ }^{b}$ NanoBRET assay $\mathrm{IC}_{50}(\mathrm{nM}, \mathrm{n}=\mathbf{2}$, nt $=$ not tested).

We propose that SGC-GAK-1 (11) and the controls SGCGAK-1N (14) and 18 can be used in parallel as a probe set to study GAK biology in cells. As an illustrative example, we used the probe set to explore the potential role of GAK in prostate cancer, ${ }^{11}$ the probe set was tested for effects on the viability of five well-characterized prostate cancer cell lines ( $\mathrm{PC}_{3}, \mathrm{DU} 145, \mathrm{LNCaP}, \mathrm{VCaP}$, and 22Rv1 cells). Western blotting experiments confirmed that GAK was expressed at similar levels in these cell lines (Figure S2). In an initial experiment, the cell lines were incubated with 11, 14, and 18 at three different concentrations (o.1, 1.o, and $10 \mu \mathrm{M}$ ), and viability was measured at $48 \mathrm{~h}$ or $72 \mathrm{~h}$. No effect was observed with the controls 14 or 18 in any of the cell lines at these concentrations. However, SGC-GAK-1 (11) showed strong growth inhibition in $\mathrm{LNCaP}, \mathrm{VCaP}$, and $22 \mathrm{Rv} 1$ cells at $10 \mu \mathrm{M}$, but minimal efffect in $\mathrm{PC}_{3}$ and
DU145 cells. In dose response 11 showed potent antiproliferative activity in LNCaP and $22 \mathrm{Rv}$ cells at the same dose range it engages GAK (Table 5). However, variable results were observed in the slow growing $\mathrm{VCaP}$ cells, pralueeventing the determination of an accurate $\mathrm{IC}_{50}$ value. Overall, these results demonstrate robust effects of $\mathbf{1 1}$ in a subset of prostate cancer cell lines.

Table 5. Prostate cancer cell line viability at $72 \mathbf{~ h}$.

\begin{tabular}{ccc} 
Compound & LNCaPa $^{\mathbf{2 2} \mathbf{R v i}^{\mathbf{a}}}$ \\
\hline $\mathbf{1 1}$ & $0.65 \pm 0.15$ & $0.17 \pm 0.05$ \\
$\mathbf{1 4}$ & $>100$ & $>100$ \\
$\mathbf{1 8}$ & $99 \pm 26$ & $>100$
\end{tabular}

$\mathrm{aIC}_{50} \pm \operatorname{SEM}(\mu \mathrm{M}),(\mathrm{n}=3)$.

Previous reports have demonstrated that GAK is required for proper mitotic progression. Specifically, siRNA knockdown of GAK in HeLa cells induced cell cycle arrest at the metaphase and increase levels of phosphorylated histone $\mathrm{H}_{3}$ Ser1o. ${ }^{24}$ Prolonged metaphase arrest is known to lead to activation of apoptotic pathways. ${ }^{25}$ We observed that treatment of $22 \mathrm{Rv} 1$ cells with 11 led to PARP cleavage, a marker of cells undergoing apoptosis (Figure $\mathbf{S}_{\mathbf{3}}$ ), and an increase in phosphorylated histone $\mathrm{H}_{3}$ Serio, as had been observed in with GAK targeting siRNA. ${ }^{24}$ Thus, our probe set demonstrated that pharmacological inhibition of the GAK kinase domain can phenocopy the effect on cell growth previously shown by depletion of GAK protein.

\section{Discussion and Conclusions}

We describe the identification of a potent, selective, and cell-active GAK probe, SGC-GAK-1 (11), its negative control SGC-GAK-1N (14), and the RIPK2 control 18. 11 was characterized for selectivity across a broad panel of kinase assays. The use of controls 14 and $\mathbf{1 8}$ can further increase confidence in GAK inhibition as the mediator of phenotypes induced by $\mathbf{1 1}$ in cells. SGC-GAK-1 (11) has several advantages over the previously reported isothiazolo[4,3b]pyridine GAK inhibitor 1, including superior cellular potency and improved kinase selectivity. The GAK probe set $(\mathbf{1 1}, \mathbf{1 4}, \mathbf{1 8})$ has been made openly available (see https://www.thesgc.org/chemical-probes/SGC-GAK-1).

We expect it will find utility in the elucidation of GAK biology.

The identification of RIPK2 as a target of $\mathbf{1 1}$ is surprising as GAK and RIPK2 belong to different branches of the kinome. Moreover, they have divergent ATP-binding pockets - of the 28 residues lining the pockets, only 14 are identical or similar. The propensity for quinolines to bind both kinases results from higher order interactions not presently understood.

The narrowed GAK/RIPK2 selectivity window in cells highlights the importance of profiling in relevant assay systems. There remains a finite possibility that cellular screening would reveal additional potent kinase (or other protein) targets of $\mathbf{1 1}$, but the KINOMEscan data suggest this is highly unlikely. 11 demonstrated a $>50$-fold difference in affinity between GAK and RIPK2 in an in vitro 
binding assay. whereas it was nearly equipotent (within 4fold affinity) on the two kinases in live cell target engagement assays that included full length protein, physiological levels of ATP, and endogenous protein partners. ${ }^{20}$ To support robust interpretation of the biology of $\mathbf{1 1}$, we identified the quinazoline $\mathbf{1 8}$ as a RIPK2 inhibitor that lacks affinity for GAK as means to control for this offtarget in cells.

The observation that GAK expression is associated with prostate cancer progression prompted us to explore the effect of GAK inhibition across a range of cell lines. To date studies of the role of GAK in prostate cancer have utilized knock-down of the whole protein. ${ }^{26}$ We now show that inhibition of the GAK kinase domain can block the growth of prostate cancer cells. Our results demonstrate that the kinase and not the auxilin-homology domain is critical for this phenotype in cells. SGC-GAK-1 (11), but not the controls 14 and 18, robustly blocked growth of ${ }_{22} \mathrm{Rv} 1$ and $\mathrm{LNCaP}$ cell lines. DU145 or $\mathrm{PC}_{3}$ cell lines were less responsive. Since neither $\mathrm{DU}_{145}$ nor $\mathrm{PC}_{3}$ express the AR, their proliferation is not expected to be AR-dependent. In contrast $\mathrm{LNCaP}$ and $22 \mathrm{Rv} 1$ are AR positive and are cell models for androgen-dependent growth. Interestingly, the most potently inhibited cell line (22Rv1) expresses the $A R-V_{7}$ and other splice variants. These splice variants are often increased in patients who become resistant to androgen deprivation. ${ }^{27}$ Why the AR- $V_{7}$ expressing lines are more sensitive and what are the mechanisms by which GAK inhibitors target a subset of AR expressing prostate cancer cells are the subjects of ongoing investigation.

In summary, we have generated the first chemical probe set for the poorly studied kinase GAK. SGC-GAK-1 (11), when used in parallel with $\mathbf{1 4}$ and $\mathbf{1 8}$, can be used to study the biology of GAK kinase inhibition in cells. We demonstrate that the GAK kinase domain is a potential target for inhibition of prostate cancer growth in cells that express AR splice variants associated with poor clinical prognosis.

\section{Experimental}

2-14 were synthesized as previously reported, and 2-9 were consistent with previous reports. ${ }^{17}$ General procedures and characterization of 10, 12, and 13 are included in the SI. All compounds were $>98 \%$ pure by ${ }^{1} \mathrm{H} /{ }^{13} \mathrm{C}$ NMR and LCMS.

General procedure for the synthesis of 4anilinoquinolines: 6-Bromo-4-chloroquinoline (1.o eq.), 3,4,5trimethoxyaniline (1.1 eq.), and i- $\mathrm{Pr}_{2} \mathrm{NEt}$ (2.5 eq.) were suspended in ethanol (30 $\mathrm{mL})$ and refluxed for $18 \mathrm{~h}$. The crude mixture was purified by flash chromatography using EtOAc:hexane followed by $1-5 \%$ methanol in EtOAc. After solvent removal under reduced pressure, the product was obtained.

6-Bromo- $\mathrm{N}$-(3,4,5-trimethoxyphenyl)quinolin-4-amine

(11) was obtained as a mustard solid (310 $\mathrm{mg}, 0.79 \mathrm{mmol}, 64 \%$ ) MP $178-180{ }^{\circ} \mathrm{C} ;{ }^{1} \mathrm{H}$ NMR (40o MHz, DMSO- $\left.d_{6}\right) \delta 11.06(\mathrm{~s}, 1 \mathrm{H}), 9.19$ $(\mathrm{d}, J=1.7 \mathrm{~Hz}, 1 \mathrm{H}), 8.48(\mathrm{~d}, J=6.9 \mathrm{~Hz}, 1 \mathrm{H}), 8.32-7.82(\mathrm{~m}, 2 \mathrm{H})$, $6.92(\mathrm{~d}, J=6.9 \mathrm{~Hz}, 1 \mathrm{H}), 6.82(\mathrm{~s}, 2 \mathrm{H}), 3.8 \mathrm{o}(\mathrm{s}, 6 \mathrm{H}), 3.72(\mathrm{~s}, 3 \mathrm{H}) ;{ }^{13} \mathrm{C}$ NMR (101 MHz, DMSO-d $\left.d_{6}\right) \delta$ 154.0, 153.6 (s, 2C), 143.0, 137.6, $136.5,136.3,132.8,126.2,122.7,119.7,118.5$, 103.0 (s, $2 \mathrm{C})$, 100.9, 60.2, $56.1(\mathrm{~s}, 2 \mathrm{C})$. HRMS-ESI $(\mathrm{m} / \mathrm{z}):[\mathrm{M}+\mathrm{H}]^{+}$calcd for $\mathrm{C}_{18} \mathrm{H}_{18} \mathrm{~N}_{2} \mathrm{O}_{3} \mathrm{Br}$ : 389.0500, found 389.0490; $\mathrm{LC}-\mathrm{T}_{\mathrm{r}}=3.60 \mathrm{~min}$, purity $>98 \%$.

2-Methyl-6-(trifluoromethyl)- $N$-(3,4,5-trimethoxyphenyl)quinolin-4-amine (14) was obtained as a yellow solid (330 mg,
$0.84 \mathrm{mmol}, 69 \%) \mathrm{MP} 240{ }^{\circ} \mathrm{C}$ decomp.; ' $\mathrm{H}$ NMR (400 MHz, DMSO- $\left.d_{6}\right) \delta_{10.87}(\mathrm{~s}, 1 \mathrm{H}), 9.20(\mathrm{~s}, 1 \mathrm{H}), 8.23(\mathrm{~s}, 2 \mathrm{H}), 6.87(\mathrm{~s}, 1 \mathrm{H})$, $6.79(\mathrm{~s}, 2 \mathrm{H}), 3.81(\mathrm{~s}, 6 \mathrm{H}), 3.73(\mathrm{~s}, 3 \mathrm{H}), 2.65(\mathrm{~s}, 3 \mathrm{H})$; ${ }^{13} \mathrm{C}$ NMR $(101$ $\left.\mathrm{MHz}, \mathrm{DMSO}-d_{6}\right) \delta 157.3,154.7,154.1$ (s, 2C), 136.9, 133.2, 129.2-129.1 $(\mathrm{m}, 1 \mathrm{C}), 126.7,126.7,126.4,125.7,123.0,122.4(\mathrm{~d}, J=3.8 \mathrm{~Hz}), 116.2$, 103.4, 102.0, 6o.6, $56.6(\mathrm{~s}, 2 \mathrm{C})$, 20.9. HRMS-ESI $(\mathrm{m} / \mathrm{z}):[\mathrm{M}+\mathrm{H}]^{+}$ calcd for $\mathrm{C}_{20} \mathrm{H}_{19} \mathrm{~F}_{3} \mathrm{~N}_{2} \mathrm{O}_{3}: 393.1426$, found 393.1413; $\mathrm{LC}-\mathrm{T}_{\mathrm{r}}=4.02$ min, purity $>98 \%$.

\section{Supporting Information}

The Supporting Information is available free of charge on the ACS Publications website at DOI: XXXXX. Compound synthesis, assay protocols, tabulated assay output, dose-response curves, and supporting figures and tables (PDF)

Molecular formula strings with in vitro activity data (CSV)

\section{AUTHOR INFORMATION}

\section{Corresponding Author}

*Phone: +1 919-962-5349. E-mail: william.zuercher@unc.edu.

\section{ORCID}

Christopher Asquith: oooo-ooo1-5871-3458

Benedict-Tilman Berger: oooo-0oo2-3314-2617

Stephen Capuzzi oooo-0oo3-0oo1-8211

David Drewry: oooo-ooo1-5973-5798

Jonathan Elkins: oooo-0oo3-2858-8929

Stefan Knapp: oooo-ooo1-5995-6494

Susanne Müller: oooo-0oo3-2402-4157

Carrow Wells: oooo-0oo3-4799-6792

Timothy Willson: oooo-0oo3-4181-8223

William Zuercher: oooo-ooo2-9836-0o68

\section{Author Contributions}

The manuscript was written through contributions of all authors. All authors approved the final manuscript version.

\section{Notes}

The authors declare no competing financial interests.

\section{ACKNOWLEDGMENT}

The SGC is a registered charity (number 1097737) that receives funds from AbbVie, Bayer Pharma AG, Boehringer Ingelheim, Canada Foundation for Innovation, Eshelman Institute for Innovation, Genome Canada, Innovative Medicines Initiative (EU/EFPIA) [ULTRA-DD grant no. 115766], Janssen, Merck KGaA Darmstadt Germany, MSD, Novartis Pharma AG, Ontario Ministry of Economic Development and Innovation, Pfizer, São Paulo Research Foundation-FAPESP, Takeda, and Wellcome [106169/ZZ14/Z]. Antti Poso and Tuomo Laitinen (University of Eastern Finland) are thanked for informative discussions. We also thank Dr. Brandie Ehrmann for LC-MS/HRMS support provided by the Mass Spectrometry Core Laboratory at the University of North Carolina at Chapel Hill.

\section{ABBREVIATIONS USED}

DSF, differential scanning fluorimetry; GAK, cyclin G associated kinase; ITC, isothermal titration calorimetry

\section{REFERENCES}

1. Kanaoka, Y.; Kimura, S. H.; Okazaki, I.; Ikeda, M.; Nojima, H., GAK: a cyclin G associated kinase contains a tensin/auxilinlike domain. FEBS Lett 1997, 402, 73-80. 
2. Sorrell, F. J.; Szklarz, M.; Abdul Azeez, K. R.; Elkins, J. M.; Knapp, S., Family-wide structural analysis of human numbassociated protein kinases. Structure 2016, 24, 401-411.

3. Kimura, S. H.; Tsuruga, H.; Yabuta, N.; Endo, Y.; Nojima, H., Structure, expression, and chromosomal localization of human GAK. Genomics 1997, 44, 179-187.

4. Sato, J.; Shimizu, H.; Kasama, T.; Yabuta, N.; Nojima, H., GAK, a regulator of clathrin-mediated membrane trafficking, localizes not only in the cytoplasm but also in the nucleus. Genes Cells 2009, 14, 627-641.

5. Dzamko, N.; Zhou, J.; Huang, Y.; Halliday, G. M., Parkinson's disease-implicated kinases in the brain; insights into disease pathogenesis. Front Mol Neurosci 2014, 7, 57.

6. Zhang, C. X.; Engqvist-Goldstein, A. E.; Carreno, S.; Owen, D. J.; Smythe, E.; Drubin, D. G., Multiple roles for cyclin Gassociated kinase in clathrin-mediated sorting events. Traffic 2005, 6, 1103-1113.

7. Eisenberg, E.; Greene, L. E., Multiple roles of auxilin and hsc7o in clathrin-mediated endocytosis. Traffic 2007, 8, 640-646.

8. Chaikuad, A.; Keates, T.; Vincke, C.; Kaufholz, M.; Zenn, M.; Zimmermann, B.; Gutierrez, C.; Zhang, R. G.; Hatzos-Skintges, C.; Joachimiak, A.; Muyldermans, S.; Herberg, F. W.; Knapp, S.; Muller, S., Structure of cyclin G-associated kinase (GAK) trapped in different conformations using nanobodies. Biochem $J$ 2014, 459, 59-69.

9. Susa, M.; Choy, E.; Liu, X.; Schwab, J.; Hornicek, F. J.; Mankin, H.; Duan, Z., Cyclin G-associated kinase is necessary for osteosarcoma cell proliferation and receptor trafficking. Mol Cancer Ther 2010, 9, 3342-3350.

10. Sakurai, M. A.; Ozaki, Y.; Okuzaki, D.; Naito, Y.; Sasakura, T.; Okamoto, A.; Tabara, H.; Inoue, T.; Hagiyama, M.; Ito, A.; Yabuta, N.; Nojima, H., Gefitinib and luteolin cause growth arrest of human prostate cancer $\mathrm{PC}-3$ cells via inhibition of cyclin G-associated kinase and induction of miR-63o. PLoS One 2014, 9, e100124.

11. Ray, M. R.; Wafa, L. A.; Cheng, H.; Snoek, R.; Fazli, L.; Gleave, M.; Rennie, P. S., Cyclin G-associated kinase: a novel androgen receptor-interacting transcriptional coactivator that is overexpressed in hormone refractory prostate cancer. Int $J$ Cancer 2006, 118, 1108-1119.

12. Knapp, S.; Arruda, P.; Blagg, J.; Burley, S.; Drewry, D. H.; Edwards, A.; Fabbro, D.; Gillespie, P.; Gray, N. S.; Kuster, B.; Lackey, K. E.; Mazzafera, P.; Tomkinson, N. C.; Willson, T. M.; Workman, P.; Zuercher, W. J., A public-private partnership to unlock the untargeted kinome. Nat Chem Biol 2o13, 9, 3-6.

13. Arrowsmith, C. H.; Audia, J. E.; Austin, C.; Baell, J.; Bennett, J.; Blagg, J.; Bountra, C.; Brennan, P. E.; Brown, P. J.; Bunnage, M. E.; Buser-Doepner, C.; Campbell, R. M.; Carter, A. J.; Cohen, P.; Copeland, R. A.; Cravatt, B.; Dahlin, J. L.; Dhanak, D.; Edwards, A. M.; Frederiksen, M.; Frye, S. V.; Gray, N.; Grimshaw, C. E.; Hepworth, D.; Howe, T.; Huber, K. V.; Jin, J.; Knapp, S.; Kotz, J. D.; Kruger, R. G.; Lowe, D.; Mader, M. M.; Marsden, B.; MuellerFahrnow, A.; Muller, S.; O'Hagan, R. C.; Overington, J. P.; Owen, D. R.; Rosenberg, S. H.; Roth, B.; Ross, R.; Schapira, M.; Schreiber, S. L.; Shoichet, B.; Sundstrom, M.; Superti-Furga, G.; Taunton, J.; Toledo-Sherman, L.; Walpole, C.; Walters, M. A.; Willson, T. M.; Workman, P.; Young, R. N.; Zuercher, W. J., The promise and peril of chemical probes. Nat Chem Biol 2015, 11, 536-541.

14. Fabian, M. A.; Biggs, W. H., 3rd; Treiber, D. K.; Atteridge, C. E.; Azimioara, M. D.; Benedetti, M. G.; Carter, T. A.; Ciceri, P.; Edeen, P. T.; Floyd, M.; Ford, J. M.; Galvin, M.; Gerlach, J. L.; Grotzfeld, R. M.; Herrgard, S.; Insko, D. E.; Insko, M. A.; Lai, A. G.; Lelias, J. M.; Mehta, S. A.; Milanov, Z. V.; Velasco, A. M.; Wodicka, L. M.; Patel, H. K.; Zarrinkar, P. P.; Lockhart, D. J., A small molecule-kinase interaction map for clinical kinase inhibitors. Nat Biotechnol 2005, 23, 329-336.
15. Tabara, H.; Naito, Y.; Ito, A.; Katsuma, A.; Sakurai, M. A.; Ohno, S.; Shimizu, H.; Yabuta, N.; Nojima, H., Neonatal lethality in knockout mice expressing the kinase-dead form of the gefitinib target GAK is caused by pulmonary dysfunction. PLoS One 2011, 6, e26034.

16. Kovackova, S.; Chang, L.; Bekerman, E.; Neveu, G.; Barouch-Bentov, R.; Chaikuad, A.; Heroven, C.; Sala, M.; De Jonghe, S.; Knapp, S.; Einav, S.; Herdewijn, P., Selective inhibitors of cyclin $\mathrm{G}$ associated kinase (GAK) as anti-hepatitis $C$ agents. J Med Chem 2015, 58, 3393-3410.

17. Asquith, C. R. M.; Laitinen, T.; Bennett, J. M.; Godoi, P. H.; East, M. P.; Tizzard, G. J.; Graves, L. M.; Johnson, G. L.; Dornsife, R. E.; Wells, C. I.; Elkins, J. M.; Willson, T. M.; Zuercher, W. J., Identification and optimization of 4-anilinoquinolines as inhibitors of cyclin G associated kinase. ChemMedChem 2018, 13, 48-66.

18. Haile, P. A.; Votta, B. J.; Marquis, R. W.; Bury, M. J.; Mehlmann, J. F.; Singhaus, R.; Charnley, A. K.; Lakdawala, A. S.; Convery, M. A.; Lipshutz, D. B.; Desai, B. M.; Swift, B.; Capriotti, C. A.; Berger, S. B.; Mahajan, M. K.; Reilly, M. A.; Rivera, E. J.; Sun, H. H.; Nagilla, R.; Beal, A. M.; Finger, J. N.; Cook, M. N.; King, B. W.; Ouellette, M. T.; Totoritis, R. D.; Pierdomenico, M.; Negroni, A.; Stronati, L.; Cucchiara, S.; Ziółkowski, B.; Vossenkämper, A.; MacDonald, T. T.; Gough, P. J.; Bertin, J.; Casillas, L. N., The identification and pharmacological characterization of 6-(tert-butylsulfonyl)- $\mathrm{N}$-(5-fluoro- $1 \mathrm{H}$ indazol-3-yl)quinolin-4-amine (GSK583), a highly potent and selective inhibitor of RIP2 kinase. J Med Chem 2o16, 59, 48674880 .

19. Fedorov, O.; Niesen, F. H.; Knapp, S., Kinase inhibitor selectivity profiling using differential scanning fluorimetry. Methods Mol Biol 2012, 795, 109-118.

2o. Vasta, J. D.; Corona, C. R.; Wilkinson, J.; Zimprich, C. A.; Hartnett, J. R.; Ingold, M. R.; Zimmerman, K.; Machleidt, T.; Kirkland, T. A.; Huwiler, K. G.; Ohana, R. F.; Slater, M.; Otto, P.; Cong, M.; Wells, C. I.; Berger, B. T.; Hanke, T.; Glas, C.; Ding, K.; Drewry, D. H.; Huber, K. V. M.; Willson, T. M.; Knapp, S.; Müller, S.; Meisenheimer, P. L.; Fan, F.; Wood, K. V.; Robers, M. B., Quantitative, wide-spectrum kinase profiling in live cells for assessing the effect of cellular ATP on target engagement. Cell Chem Biol 2018, 25, 206-214.e11.

21. Tigno-Aranjuez, J. T.; Benderitter, P.; Rombouts, F.; Deroose, F.; Bai, X.; Mattioli, B.; Cominelli, F.; Pizarro, T. T.; Hoflack, J.; Abbott, D. W., In vivo inhibition of RIPK2 kinase alleviates inflammatory disease. J Biol Chem 2014, 289, 2965129664.

22. Casillas, L. N.; Demartino, M. P.; Haile, P.; Mehlmann, J. F.; Ramajulu, J. M.; Singhaus, R. J. Amino-Quinolines as Kinase Inhibitors. WO2014/043437, 2014.

23. Casillas, L. N.; Haile, P. A.; Marquis, R. W. J.; Wang, G. Prodrugs of Amino Quinazoline Kinase Inhibitor. WO2014/o43446, 2014.

24. Shimizu, H.; Nagamori, I.; Yabuta, N.; Nojima, H., GAK, a regulator of clathrin-mediated membrane traffic, also controls centrosome integrity and chromosome congression. J Cell Sci 2009, 122 (Pt 17), 3145-3152.

25. Orth, J. D.; Loewer, A.; Lahav, G.; Mitchison, T. J., Prolonged mitotic arrest triggers partial activation of apoptosis, resulting in DNA damage and $\mathrm{p} 53$ induction. Mol Biol Cell 2012, 23, 567-576.

26. Dolly, S. O.; Gurden, M. D.; Drosopoulos, K.; Clarke, P.; de Bono, J.; Kaye, S.; Workman, P.; Linardopoulos, S. RNAi screen reveals synthetic lethality between cyclin G-associated kinase and $\mathrm{FBXW}_{7}$ by inducing aberrant mitoses. $\mathrm{Br}$ J Cancer 2017, 117, 954-964.

27. Dehm, S. M.; Tindall, D. J., Alternatively spliced androgen receptor variants. Endocr Relat Cancer 2011, 18, R183-R196. 
Table of Contents Graphic

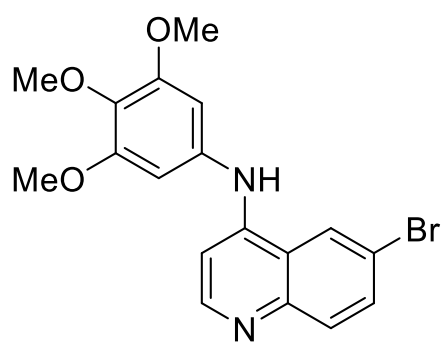

\section{SGC-GAK-1}

GAK DSF $\triangle T_{m} 7.7^{\circ} \mathrm{C}$

GAK K $\mathrm{K}_{\mathrm{i}}=3.1 \mathrm{nM}$

GAK nanoBRET IC $50=120 \mathrm{nM}$

NAK selectivity - 16000

$>50$-fold selectivity over nearest kinase 